\title{
Effects of High-Dose Fentanyl on Renal Haemodynamics in Conscious Dogs
}

The renal haemodynamic effects of high doses of fentanyl were examined in 17 unanaesthetized, chronically implanted dogs, in order to avoid the confusing effects of superimposed anaesthesia and acute surgical procedures Ten to fourteen days prior to the study, a Doppler flow probe was positioned around the left renal artery and a Tygon catheter was placed into the lower abdominal aorta through a lumbar arterial side branch. During the experiments, the trained animals were lying quietly on their right side. Following steady-state awake baseline measurements, an intravenous fentanyl infusion, $25 \mu \mathrm{g} \cdot \mathrm{kg}^{-1}$ (lower dose), or $50 \mu \mathrm{g} \cdot \mathrm{kg}^{-1}$ (higher dose) was administered over a ten-minute period. Anterial pres. sure, renai blood flow, calculated renal vascular resistance and arterial blood gases were measured for 20 minutes following the infusion. Observations were made during spontancoks and controlled ventilation, with $\mathrm{FlO}_{2}=0.21$ or 1.0. Fentanyl increased arterial pressure 10-40 per cent in all groups and did not, as a rule, significanthy affect renal blood fiow. Thus renal vascular resistance was increased. There were no significant differences between effects of the $25 \mu \mathrm{g} \cdot \mathrm{kg}^{-t}$ and the $50 \mu \mathrm{g} \cdot \mathrm{kg}^{-1}$ doses of fentanyl. It is concluded that these doses of fentanyl, given to the conscious, normovolaemic dog, result in renal vasoconstriction.

Renal blood flow does not decrease, however, impiying that auroregulation remains intact. These changes are a result of fentanyl, per se, rather than secondary to changes in oxygenation and carbon dioxide levels in the blond and do not appear to have a dose response relationship in the dosage range studied.

Key Words

ANAESTHETICS, INTRA VENOUS: Fentanyl; KIDNEY: Blood Flow.

From the Department of Anesthesiology, University of Texas Medical Branch, Galveston, Texas.

Address correspondence to: Lawrence L. Priano MD, PHD, Department of Anesthesiology E-91, University of Texas Medical Branch, Galveston, Texas 77550.
High-dose morphine has been advocated for use in patients with compromised cardiovascular status in order to achieve better haemodynamic stability.' Subsequent investigations have indicated that, although generalized haemodynamics may remain stable under such conditions, undesirable changes in regional haemodynamics can occur. ${ }^{2}$ The cardiovascular system seems to be more hyperdynamic during anaesthesia with narcotic drugs than it does during traditional inhalation anaesthesia. ${ }^{3}$ Fentanyl has been recommended because it appears to offer even greater haemodynamic stability than morphine ${ }^{4-7}$ This apparent stability might be related to less release of histamine with fentanyl than with morphine. ${ }^{8}$ However, one must still be concerned about the stability of regional haemodynamics when high doses of fentanyl are given. Recent data related to myocardial perfusion substantiates this concern. ${ }^{9}$ The renal vasculature has received little attention in this regard. One study in dogs anaesthetized with thiopentone, using a PAH clearance technique, has indicated that high doses of fentanyl do not decrease renal plasma flow. However, urine output and free water clearance were diminished along with an increase in urine osmolarity indicating an $\mathrm{ADH}$ mechanism. ${ }^{10}$ More recently, in a study in man, it was reported that fentanyl did not change creatinine clearance, urine osmoladity, or blood vasopressin concentrations. ${ }^{11}$ The intent of the present study was to examine the effects of highdose fentanyl on renal perfusion in a chronically implanted conscious animal model in which the pharmacological effects of fentanyl would not be influenced by the simultaneous presence of other anaesthetic agents, stress or the surgical procedure.

\section{Methods}

This study was done on 17 healthy, mongrel dogs of either sex weighing $20-30 \mathrm{~kg}$. The animals had no 
respiratory infections, had minimum haematocrits not lower than 40 volumes per cent and were double serum negative for diroflaria of heart worms. Implantation of the animals was done under endotracheal halothane/nitrous oxide anaesthesia with spontaneous breathing. With the animals in the supine position, a midline laparotomy was done. A four- or six-millimeter Doppler ultrasonic fow probe (L\&M Electronics, Daly City, CA) was positioned around the left main renal artery. A small Tygon catheter was introduced via a lumbar arterial side branch and positioned into the lower abdominal aorta with its tip facing proximally. The instrumentation wires and catheter were then run subcutaneously and exteriorized at an intrascapular site. The anirnals were then allowed to recover for 10-14 days. During that time, they were positioned on the experiment table three times a week. This enabled thern to become accustomed to the experimental surroundings and conditions.

Aortic pressure was measured from the previously implanted Tygon catheter with a mercurycalibrated P23ID strain gauge manometer (Statham Instruments Inc., Oxnard, CA). Renal arterial blood flow was measured with a Doppler ultrasonic flow meter (L\&M Electronics, Model 1012, Daly City, CA) using a hardwire connection to the implanted probes. This system has an accurate electronic zero. Prior to implantation, all probes were calibrated with a mechanical perfusion system. Specifically, a probe was placed around a section of dog iliac artery. Then flow through that artery was accomplished with a variable speed zoller pump using heparinized dog blood. The flow was precisely quantitated with a graduated cylinder and stopwatch over a range of $50-350 \mathrm{ml} /$ minute and a regression curve was established for each flow probe. Data were continuously recorded on a Gould-Brush direct writing oscillograph (GouldBrush, Cleveland, $\mathrm{OH}$. Renal vascular resistance was calculated by dividing the mean arterial pressure in millimeters of mercury by the mean renal blood flow in milliliters per minute. Samples for analysis of arterial partial pressure of oxygen $\left(\mathrm{PaO}_{2}\right)$ and carbon dioxide $\left(\mathrm{PaCO}_{2}\right)$ were withdrawn from the arterial catheter and analyzed on an Instrumentation Laboratory model $813, \mathrm{pH}$ blood gas analyzer.

The animals were divided into three groups. Group I breathed room air spontaneously. Group II breathed room air spontaneously for an initial set of controls and then breathed 100 per cent oxygen spontaneously through a canine anaesthesia mask connected to a semiclosed circle system. In this group a second set of controls was recorded while the animals were breathing oxygen, before the administration of fentanyl. Group III breathed room air for an initial set of controls, then breathed 100 per cent oxygen through the canine anaesthesia mask while a second set of controls was taken as did the animals in Group II. Then, one-quarter of the way through the administration of fentanyl, a point at which the animals showed signs of significant sedation, $0.1 \mathrm{mg} / \mathrm{kg}$ of dimethyltubocurarine was administered intravenously. This facilitated control of the animal's ventilation for the remainder of the experimental period. Dimethyltubocurarine was chosen because it does not produce significant haemodynamic changes. ${ }^{12}$ Controlled manual ventilation (CMV) was accomplished with the canine anaesthesia mask connected to a semiclosed circle system. The lungs were ventilated manually with a bag; ventilation was aided by an in-line Wright respirometer on the expiratory limb to quantitate tidal volumes. At the end of the experiment dimethyltubocurarine was reversed with appropriate doses of neostigmine and atropine and manual ventilation continued until the animals breathed adequately on their own.

In all three groups, $25 \mu \mathrm{g} \cdot \mathrm{kg}^{-1}$ or $50 \mu \mathrm{g} \cdot \mathrm{kg}^{-1}$ of fentanyl were administered over a ten-minute period. Data were collected for an additional 20 minutes after the end of the infusion for a total recording period of 30 minutes from the start of drug infusion. Changes were measured at $2 \frac{1}{2}, 5,10$, 15,20 and 30 minutes in all three groups and were compared statistically with the room air control value of each group by use of Student's paired t-test. Thus each animal served as its own control. The room-air breathing control was used because there were no significant changes in renal haemodynamics on transition from breathing room air to oxygen. Statistically significant changes were indicated by a $p$ value of less than 0.05 . Both dosages were administered to each animal in a random sequence on separate days. Intervals of 24 hours were allowed to elapse after an animal had received the lower dose of fentanyl, and 48 hours after receiving the higher dose of fentanyl, before the next experiments were done in that animal. 


\section{REN AL}

FENTANYL - AIR NORMOVOLAEMIA
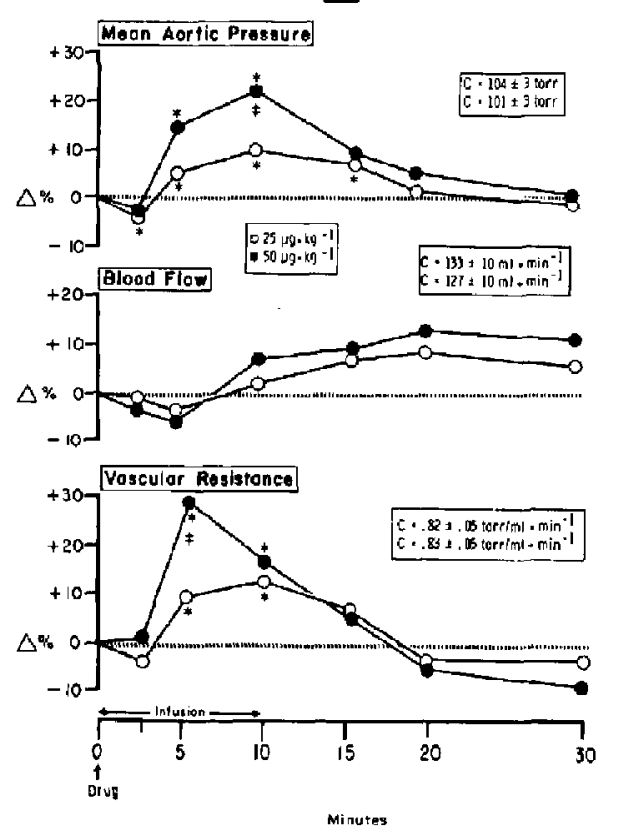

FIGURE 1 Renal Haemodynamic Effects of $25 \mu \mathrm{g} \mathrm{kg}^{-1}$ and $50 \mu \mathrm{g} \cdot \mathrm{kg}^{-1}$ of Fentanyl While Animals Breathed Room Air Spontaneously. Illustrated here are the mean per cent changes from control in aortic pressure, renal blood flow and renal vascular resistance for the Group I animals breathing air. The insets refer to the mean actual control values + SEM for that variable. Time is plotted on the abscissa in minutes. The infusion took place during the first ten minutes and variables were measured for an additional 20 minutes. Open circles refer to the lower dose of fentanyl, closed circles refer to the

higher dose of fentanyl. Asterisks indicate statistically significant changes ( $p<0.05$ ) within groups from that group's actual control value. Double crosses indicate statistically significant differences at any one time point between the low- and high-dose animals.

\section{Results}

Group One (Air with Spontaneous Ventilation, $n=$ 12, (Figure 1)]

With the animal breathing room air spontancously, both doses of fentanyl caused significant elevation of arterial pressure during the first 5 to 15 minutes of the observation period. During the latter portion of the observation period, arterial pressure returned to values not significantly different from controls. With the exception of the change at ten minutes, there were no significant differences between the low and high doses for arterial pressure in this group. Renal blood flow did not change significantly from the control value during the entire observation period with ejther dose of fentanyl, although it increased slightly during the last fifteen minutes. Renal vascular resistance was significantly elevated at five and ten minutes with both dosages of fentanyl, but only at the five minute point was the difference between the two dosages significant.

Group Two IOxygen with Spontaneous Ventilation, $n=5$, (Figure 2)]

There were no significant changes in arterial pressure, renal blood flow or renal vascular resistance in the transition from breathing room air to breathing 100 per cent oxygen during the control periods. Both dosages of fentanyl slightly decreased arterial pressure at $2 \frac{1}{2}$ minutes. Thereafter, arterial pressure increased significantly for most of the remainder of the observation period. There were no significant differences between the two dosages for this variable. Renal blood flow showed no statistically significant changes from the control levels with the exception of the five-minute value in the high dose group, when it was significantly decreased by 16 per cent. As in the room-airbreathing animals, renal blood flow increased late in the obscrvation period, but not to a significant degree. There were also no statistically significant differences between the two dosages for this variable. Renal vascular resistance was significantly elevated from 5 to 15 minutes. During the latter part of the observation period it retumed to levels not significantly different from control values. There were no differences between dosages for this variable as well.

Group Three lOxygen with Controlled Manual Ventilation, $n=5$, (Figure 3 )j

Again there were no significant differences in blood pressure, renal blood flow or renal vascular resistance in the transition from breathing room air to breathing oxygen during the control period. During the oxygen breathing portion the tidal volume and respiratory rate were measured with the in-line Wright respirometer. Early in this study, at the time of starting controlled manual ventilation, we attempted to reproduce that amount of ventila- 
tion that had been observed during spontaneous breathing with oxygen before drug administration. Despite this, we found that the $\mathrm{PaCO}_{2}$ increased after fentanyl had been given. To maintain normocarbia during fentanyl, it was necessary to ventilate the animals $30-40$ per cent more than they had breathed during spontaneous ventilation. At $2 \frac{1}{2}$ minutes, arterial pressure was significantly decreased in the low-dose group. Thereafter, arterial pressure increased significantly in this group at 10 and 15 minutes. In the high-dose group arterial pressure was significantly elevated for most of the observation period. These elevations were significantly greater than those in the low-dose group at 10,15 and 20 minutes. Renal blood flow was not significantly changed from its control value in the low-dose group, but in the high-dose group renal blood flow was significantly increased from control at 15, 20 and 30 minutes. However, these changes were not statistically different between the two dosage groups. Renal vascular resistance was significantly decreased with both dosages at $2 \frac{1}{2}$ minutes. Thereafter it increased significantly at five and ten minutes in the high-dose group and at ten minutes in the low-dose group. Later, renal vascular resistance returned to values not significantly different from the baseline. There were no significant differences between dosages for renal vascular resistance.

The data related to blood gases are contained in Table I. In Group I breathing room air, the $\mathrm{PaCO}_{2}$ was significantly increased with both dosages of fentanyl. There was a significantly greater degree of elevation of $\mathrm{PaCO}_{2}$ in the high-dose group at 5,10 , and 15 minutes. The $\mathrm{PaO}_{2}$ decreased significantly with both dosages while breathing RA and to a significantly greater degree in the high-dose group at 10 and 15 minutes. In Group II breathing oxygen, $\mathrm{PaCO}_{2}$ increased significantly in both dosage groups and there was a statistically greater difference between dosages at ten minutes. With both changes however, the $\mathrm{PaCO}_{2}$ elevation was significantly greater than the comparable dose in the room air group. As anticipated, $\mathrm{PaO}_{2}$ increased while breathing oxygen and remained elevated during fentanyl administration. In Group III, which breathed oxygen and had a normal $\mathrm{PaCO}_{2}$ maintained by controlled manual ventilation, $\mathrm{PaCO}_{2}$ did not change in the transition from breathing RA to breathing oxygen during the control period.

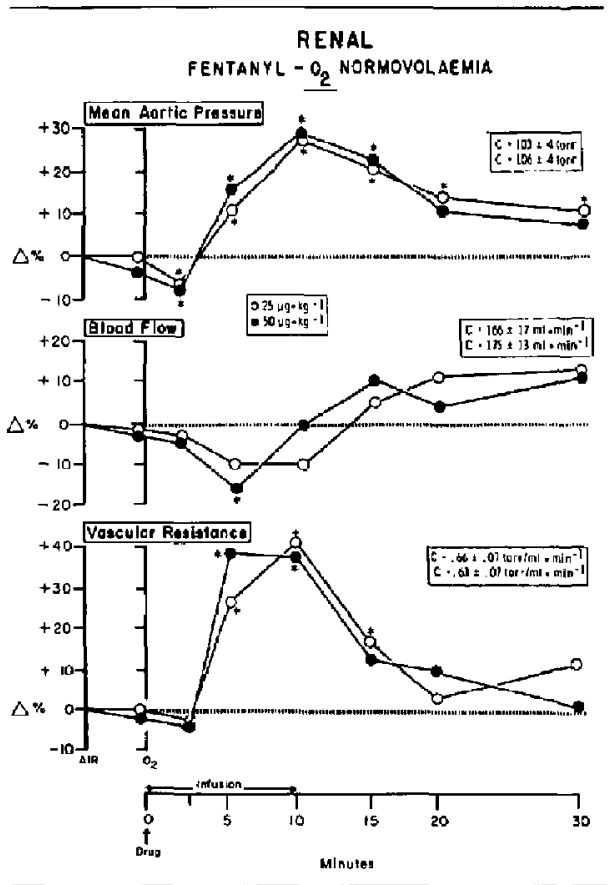

FIGURE 2 Renal Haemodynamic Effects of $25 \mu \mathrm{g} \cdot \mathrm{kg}^{-1}$ and $50 \mu \mathrm{g}^{-\mathrm{kg}^{-1}}$ of Fentanyl While Animals Breathed Oxygen Spontaneously. Illustrated here are the mean per cent changes from control in aortic pressure, renal blood flow and renal vascular resistance for the Group II animals breathing oxygen. Two sets of controls were raken before fentanyl - one while breathing room air and one while breathing oxygen. The insets refer to the mean actual control values + SEM for that variable while brealhing room air. Time is plotted on the absscissa in minutes. The infusion took place during the first ten minutes and variables were measured for an additional 20 minutes. Open circles refer to the lower dose of fentanyl, closed circtes refer to the higher dose of fentanyl. Asterisks indicate statistically significant changes $(p<0.05)$ within groups from that group's actual room air control values.

The $\mathrm{PaCO}_{2}$, with the exception of the $2 \frac{1}{2}$-minute value in the high-dose group, did not change significantly during fentanyl. The $\mathrm{PaCO}_{2}$ was significantly less than it was in the animals spontaneously breathing room air or oxygen. The $\mathrm{PaO}_{2}$ in this group was not significantly different from the $\mathrm{PaO}_{2}$ in group II breathing oxygen spontaneously.

\section{Discussion}

The results of this study demonstrated that when $25 \mu \mathrm{g} \cdot \mathrm{kg}^{-1}$ to $50 \mu \mathrm{g} \cdot \mathrm{kg}^{-1}$ of fentanyl were admin- 


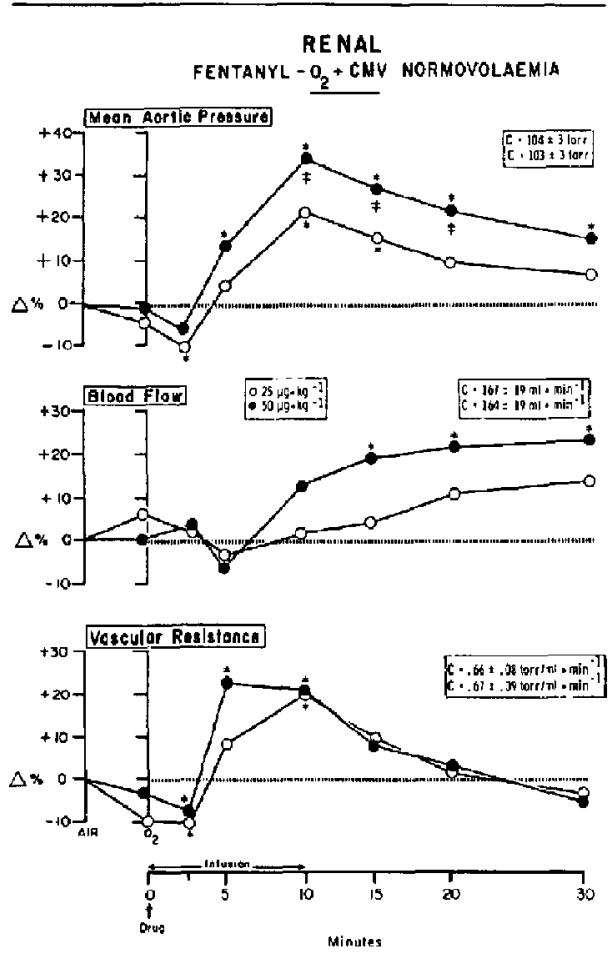

FIGURE 3 Renal Haemodynamic Effects of $25 \mu \mathrm{g} \cdot \mathrm{kg}^{-1}$ and $50 \mu \mathrm{g} \cdot \mathrm{kg}^{-1}$ of Fentanyl During Controlled Manual Ventilation (CMV) with Oxygen. Illustrated here are the mean per cent changes from control in aortic pressure, renal blood flow and renal vascular resistance for the Group III animals whose ventilation was controlled. Two sets of controls were takem before fentanyl and CMV - one while the animal was breathing room air spontaneously and one while breathing oxygen spontaneously. The insets refer to the mean actual control val ues + SEM for that variable while breathing room air. Time is plotted on the abscissa in minutes. The infusion took place during the first ten minutes and variables werc measured for an additional 20 minutes. Open circles refer to the lower dase of fentanyl, closed circles refer to the higher dose of fentanyl. Asterisks indicate statistically significant changes $(\mathrm{p}<0.05)$ within groups from that group's actual room air control values. Double crasses indicate statistically significant differences at any one time point between the low- and high-dose animals.

istered to conscious, normovolaemic dogs, renal blood flow was preserved. This occurred in spite of changes in arterial pressure. If autoregulation is defined as a stable flow over a range of perfusion pressures then autoregulatory ability remained intact in the renal vascular bed with these doses of fentanyl.

The mechanism of these changes was not examined in this study. It would appear there is a biphasic renal vascular response to fentanyl. In an isolated perfused dog hind limb preparation, it has been shown that, initially, intra-arterial doses of fentanyl produced a vascular smooth muscle relaxation followed by a constrictor-type effect. ${ }^{13}$ In the present study, initially arterial pressure and renal vascular resistance decreased slightly, to be followed by an elevation of both. These early dilation effects were probably related to a direct relaxant action of fentanyl on renal resistance vessels. This was followed by constriction not only in the renal bed itself, but also systemically. This latter effect was most likely due to a centrally mediated catecholamine release. Several human studies have examined catecholamine levels after fentanyl. The results are conflicting and range from no change, ${ }^{14}$ to a decrease, ${ }^{11.15}$ to a large increase ${ }^{16}$ in catecholamines. The reason for these discrepancies is not clear. There are technical difficulties related to the measurement of catecholamines. Differences in technique may be the explanation. These were all human data and there are no comparable studies in dogs related to catecholamine levels and fentanyl. Likewise, there is a scarcity of data describing the generalized cardiovascular effects of fentanyl in conscious animals. Studies in dogs previously anesthetized with thiopentone or pentobarbitone showed that high-dose fentanyl depressed cardiac output. This should have resulted in reflex increases in peripheral resistance to maintain blood pressure. In actuality, peripheral resístance remained unchanged and blood pressure decreased. ${ }^{4.10 .17}$ Such a response was not seen in our conscious animals as blood pressure always increased after fentanyl. This was probably due to an increase in total peripheral resistance which is not seen in the animal whose brain stem has been depressed by preceding administration of barbiturates. Morphine, like fentanyl, is a central nervous system sedative, yet it has been shown to release catecholamines from both the adrenal medulla, ${ }^{18}$ as well as from peripheral nerves. ${ }^{19}$ Our hypothesis is that fentanyl has a similar action that becomes masked when other anesthetic drugs are present. In fact under such conditions, it may even appear to be sympathoinhibitory. ${ }^{20,21}$ In conscious animals, the adrener- 


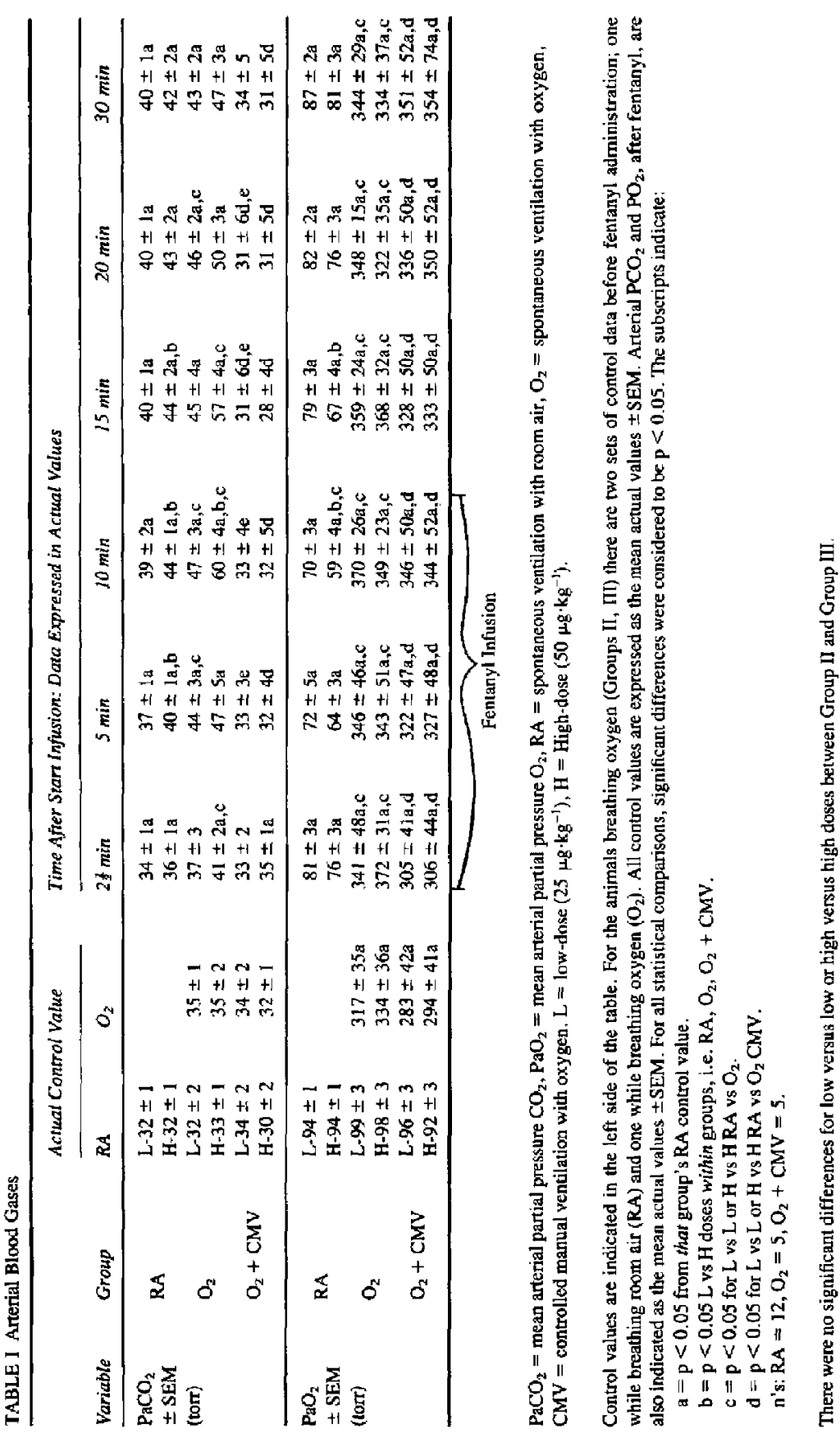


gic stimulation from fentanyl is allowed to become manifest and vascular resistance increases as noted here specifically in the kidney, as we did not measure cardiac output. In addition to direct vasoconstrictor effects of catecholamines, it is possible that they are also acting indirectly by releasing renin, with a subsequent elevation of angiotensinII. This too could contribute to the changes in renal vascular resistance noted here. Patients who received $100 \mu \mathrm{g} \cdot \mathrm{kg}^{-1}$ of fentanyl did not show a statistically significant change in their renin levels; however, the mean values presented did increase 35 per cent. ${ }^{\text {il }}$

No attempt was made here to assess renal function as this requires placement of a bladder catheter for urine samples. This was considered undesirable in our conscious unrestrained animal model. One other study has examined renal function in dogs anaesthetized with thiopentone, then given $100-1000 \mu \mathrm{g} \cdot \mathrm{kg}^{-1}$ of fentanyl. Decreases in urine volume and free-water clearance and increases in urine osmolality were noted leading to postulation of an ADH mechanism. ${ }^{10} \mathrm{~A}$ more recent study was not able to demonstrate increases in ADH in humans given $100 \mu \mathrm{g} \cdot \mathrm{kg}^{-1}$ of fentanyl. ${ }^{11}$ The results of the earlier study may have been influenced by the presence of barbiturates which can cause ADH release. ${ }^{22}$ These reports again illustrate the difference in pharmacologic results between anaesthetized and conscious subjects.

In those cases in which fentanyl is usually employed, there is often concern for the maintenance of renal perfusion yet few investigations have been done along these lines in animals or in humans. One other study of renal blood flow with fentanyl has been done in dogs, but the animals had received thiopentone. A PAH clearance-renal plasma-flow technique was used to index renal blood flow. These authors did not see a statistically significant change in RPF after fentanyl. ${ }^{10}$ However, a closer look at their data reveals that blood pressure decreased, RPF increased 11-25 per cent and calculated renal vascular resistance decreased $20-33$ per cent. These changes are opposite to those seen here. Thiopentone could certainly account for the differences as it decreases renal vascular resistance. ${ }^{23}$ Another possibility could be a dng interaction phenomenon.

In the present study, the results observed are most likely due to fentanyl itself, rather than to secondary changes in the ventilation or oxygenation. When the decreases in $\mathrm{PaO}_{2}$ were prevented by administration of oxygen (Group II), the renal haemodynamic events in response to fentanyl were the same as those seen in animals breathing room air (Group I). Hypoxaemia, then, was not the cause of the results. When oxygenation was maintained and increases in $\mathrm{PaCO}_{2}$ prevented with controlled manual ventilation (Group III), the results were the same except for some small quantitative differences. The fact that arterial pressure was greater in Group III might be related to the fact that more fentanyl gets into the brain with normocarbia than when with hypercarbia. ${ }^{24}$ This lack of effect of arterial blood gas changes on renal haemodynamics has been observed in previous studies. ${ }^{25}$ In contrast to the brain and heart, the kidney is not an organ whose blood flow is regulated by metabolic mechanisms. In actual fact, it has luxury perfusion with the usual arterial-venous oxygen difference being two to three volumes per cent.

The arterial blood gas data obtained are interesting and perhaps warrant separate investigation. During the first ten minutes, the per cent decrease in $\mathrm{PaO}_{2}$ exceeded the per cent increase in $\mathrm{PaCO}_{2}$, thus the hypoxaemia was not totally due to hypoventilation. Other explanations for this hypoxaemia include shunt and $V / Q$ mismatch phenomena in the lung as well as cardiac output depression. ${ }^{26}$ Additionally, in order to maintain normocarbia, it was necessary to ventilate the animals on controlled manual ventilation at minute volume $30-40$ per cent greater than when the animals breathed by themselves. This might have been due to a bronchodilatory action of fentanyl itself or the released catecholamines both of which would increase physiologic deadspace. Another possibility could be increased $\mathrm{CO}_{2}$ production associated with increased tissue metabolism due to catecholamine release.

One disadvantage of a direct-measuring flow technique, such as the one used here, is that it does not give information about changes in intra-organ. blood flow distribution as can be seen for instance with radioactive microspheres. The main goal of this study was to investigate the effects of fentanyl in a completely normal animal whose homeostasis had not been violated by other superimposed anaesthetics or surgical procedures. The flow-probe techrique is the most practical and physiologic for use in chronic animals. Pentobarbital results in 
deterioration of cardiac output and elevation of peripheral resistance with both spotaneous ${ }^{27}$ and controlled ${ }^{28}$ ventilation. Heart rate is grossly abnormal due to both a vagolytic and baroreceptor mechanism. ${ }^{28}$ In addition, pentobarbital and other anaesthetics, commonly used in animal studies, markedly depress peripheral chemoreceptor reflexis. ${ }^{29}$ All of those can have a significant impact on peripheral perfusion and thus influence pharmacologic studies of this nature.

In summary, this study has shown that high doses of fentanyl produce renal vasoconstriction. Renal blood flow is maintained probably through an autoregulatory mechanism. These changes do not appear to be dose-related and are independent of changes in ventilation and oxygenation. They can be contrasted with morphine and meperidine, both of which dilate the renal bed under similar experimental conditions and seem to do so in a doserelated manner. ${ }^{25,30}$ It is hypothesized that these changes are due to a centrally or a peripherally mediated increase in adrenergic activity. The precise mechanisms remain to be elucidated by future investigations.

\section{Acknowledgements}

The clerical expertise and patience of Sandra Doucette, who prepared the table and text, are greatly appreciated, as are the skills of Sandra Baxter and Byron Cline of the Medical Illustration and Photography division, Shriners Burns Institute, for their work on the figures. Special recognition is due Bettina Marrone for her invaluable technical support. Her care and attention to chronically instiumented animals as well as her skills related to thei: preparation for an actual performance of the experiments has been invaluable. Without such efforts, this study could not have been accomplished.

\section{References}

1 Lowenstein E, Hallowell T, Levine FH, Daggett WM, Austen WG, Laver MB. Cardiovascular responses to large doses of intravenous morphine in man. N Engl J Med 1969; 281: 1389-93.

2 Vaner $S F$, Marsh JD, Swain JA. Effects of morphine on coronary and left ventricular dynamics in conscious dogs. J Clin Invest 1975; 55: 207-17.

3 Arens JF, Benbow BP, Ochsner JL, Theard R. Morphine anesthesia for aortocoronary bypass pro- cedures. Anesth Analg 1972; 51: 901-9.

4 LiuWS, Bidwai AV, Stanley TH, Isern-Amaral J. Cardiovascular dynamics after large doses of fentanyl and fentanyl plus nitrous oxide in the dog. Anesth Analg 1976; 55: 168-72.

5 Stanley $T H$, Webster $L R$. Ancsthetic requirements and cardiovascular effects of fentanyl oxygen and fentanyl diazepam oxygen anesthesia in man. Anesth Analg 1978; 57: 411-6.

6 Lunn JK, Stanley TH, Eisele J, Webster L, Wood. ward $A$. High dose fentanyl anesthesia for coronary artery surgery: plasma fentanyl concentrations and influence of nitrous oxide on cardiovascular responses. Anesth Analg 1979; 58: 390-5.

7 Waller $J L, H u g$ CC, Nagle DM, Craver $J M$. Hemodynamic changes during fentanyl oxygen anesthesia for aortocoronary bypass operation. Anesthesiology 1981; 55: 212-7.

8 Rosow CE, Moss J. Philbin DM. Savarese JJ. Histamine release during morphine and fentany] anesthesia. Anesthesiology 1982; 56: 93-6.

9 Sonntag $H$, Larsen R, Hilfiker O, Ketrler D, Brackschnieder $B$. Myocardial blood flow and exyen consumption during high dose fentanyl anesthesia in patients with coronary artery disease. Anesthesiology 1982; 56: 417-22.

10 Bidwai AV, Liu WA, Stanley TH, Bidwai V, Loeser $E A$, Shaw $C L$. Effects of large doses of fentanyl and fentanyl with nitrous oxide on renal function in the dog. Can Anaesth Soc J 1976; 23: 296-302.

11 Kono K, Philbin OM, Coggins CH. et al. Renal function and stress response during halothane or fentanyl anesthesia. Anesth Anal 1981; 60: 552-6.

12 MeCullough LS, Stone WA, Delaunois AL, Reier $C E$, Hamelberg $W$. Effect of dimethyltubocurarine iodide on cardiovascular parameters, post ganglionic sympathetic activity and histamine release. Anesth Analg 1972; 51: 554-9.

13 Freye $E$. The effect of fentanyl on the resistance and capacitance vessels of the dog's hind limb. ArzneimForsch Drug Research 1977; 27: 1037-9.

14 Jaatieia A, Nikki P, Takki S, Tammisto T. Effect of dextromoramide fentanyl and morphine on the plasma catecholamine levels. Ann Clin Res 1971; 3: 107-11.

15 Stanley TH, Berman L, Green O, Robertson D. Plasma catecholamine and cortisol responses to fentanyl oxygen anesthesia for coronary antery operations. Anesthesiology 1980; 53: 250-3.

16 Hicks HC, Mowbray AC, Yhap EO. Cardiovascular 
effects of and catecholamine responses to high dose fentanyl oxygen for induction of anesthesia in patients with ischemic coronary artery disease. Anesth Analg 1981; 60: 563-8.

17 Freye E. Cardiovascular effects of high dosages of fentanyl, meperidine and naloxone in dogs. Anesth Analg 1974; 53: 40-7.

18 Fennessey MR, Ortiz A. Studies on the morphine induced release of catecholamines from adrenal glands in the dog. Eur J Pharmacol 1968; 3: 177-85.

19 Klingman GE, Maynert EW. Tolerance to morphine. III. Effects on catecholamines in the heart, intestine and spleen. J Pharmacol Exp Ther 1962; 135: $300-5$.

20 Laubie M, Schmint H, Canellas J, RoquebertJ, Demichel $P$. Centrally mediated bradycardia and hypotension induced by narcotic analgesics dextromoramide and fentanyl. Eur J Pharmacol 1974; 28 : 66-75.

21 Daskalopoulos NT, Laubie M, Schmitt H. Localization of the central sympatho-inhibitory effect of a narcotic analgesic fentanyl in cats. Eur J Pharmacol 1975; 33: 91-7.

22 Pitts RF. Physiology of the kidney and body fluids. 1st Ed. Chicago: Yearbook Medical Publishers (1963).

23 Priano $L L$. Alterations of renal hemadynamics by thiopental, diazepam and ketamine in conscious dogs. Anesth Analg 1983; in press.

24 Ainslie SG, Eisele JH, Corkill G. Fentanyl concentrations in brain and serum during respiratory acid-base changes in the dog. Anesthesiology 1979; 51:293-7.

25 Priano $L L$, Vatner $S F$. Morphine effects on cardiac output and regional blood flow distribution in conscious dogs. Anesthesiology 1981; 55: 236-43.

26 Goldberg AH, Padget CH. Comparative effects of morphine and fentanyl on isolated heart muscle. Anesth Analg 1969; 48: 978-82.

27 Priano, $L L$, Traber DL Wilson RD. Barbiturate anesthesia - an abnormal physiological situation. J Pharmacol Exp Ther 1969; 165: 126-35.

28 Manders WT, Vatner SF. Effects of sodium pentobarbital anesthesia on left ventricular function and distribution of cardiac output in dogs with particular reference to the mechanism for tachycardia. Circ Res 1976; 39: 512-7.

29 Zimpfer $M$, Sit SP, Vatner SF. Effects of anesthesia on the canine carotid chemoreceptor reflex. Circ Res 1981; 48: 400-6.
30 Priano $L L$, Vainer SF, Generalized cardiovascular and regional hemodynamic effects of meperidine in conscious dogs. Anesth Analg 1981; 6: 649-54.

\section{Résumé}

On a exploré les effets causés par de fortes doses de fentanyl chez 17 chiens non-anesthésiés, chroniquement préparés, afin d'eviter les effets incerzains de l'anesthésie surajoutée et des opérations aiguës. De dix à quatorze jours avant notre expérience, une sonde Doppler a été placée autour de l'artère gauche et un cathéter Tygon a été inséré dans l'aorte du bas ventre d travers la branche lombaire artérielle du côté. Durant le cours de notre expérience, les animaux d'essais étaient couchés sars bouger sur le côté droit. Aprés avoir controle les mesures de base des chiens éveillés, une infusion intraveineuse de fentanyl, $25 \mu \mathrm{g} \cdot \mathrm{kg}^{-1}$ (basse dose) et $50 \mu \mathrm{g} \cdot \mathrm{kg}^{-t}$ (dose plus forte) fut administrée pendant une période de dix minutes. La tension arterielle, le débit san guin rénal, la résistance vasculaire rénale calculée et l'analyse artérielle des gaz du sang ont été mesurés pendant les vingt minutes suivant l'infusion. On a fait des observations pendant la ventilation spontanée et contrôlée avec le $\mathrm{FlO}_{2}=0.21$ ou 1.0. Le fentanyl augmenta la pression artérielle de 10 d 40 pour cent chez tous les groupes. mais $n$ 'influença pas de manière significative, comme d'usage, le débit sanguin rénal. Donc, la résistance vasculaire rénale augmenta. $l l n^{\prime} y$ a donc pas de différences significatives entre la dose de $25 \mathrm{\mu g} \cdot \mathrm{kg}^{-1}$ et celle de $50 \mu \mathrm{g} \cdot \mathrm{kg}^{-l}$ de fentanyl. Nous conciuons donc que ces doses de fentanyl administrées aux chiens éveillés et normovolémiques influencent la vasoconstriction rênale. Le débit sanguin rénal ne baissa pas mais laisse cependant sous-entendre que l'autorégulation de la circulation rénale reste intacte. Ces changements sont donc produits par le fentanyl même, plutôt que les changements secondaires d' oxygénation et de gaz carbonique sanguins et n' apparaissent pas avoir de rapport avec la dose réponse des doses étudiées. 